\title{
Comparison between different methods of sonographic cervical length assessment during pregnancy
}

\author{
El Sayed El Badawy Mohamed Abd Naby Awad ${ }^{1,2}$, Tamer Mamdouh Abdel Dayem ${ }^{1,2}$, \\ Ahmed Mohammed Samy El-Agwany ${ }^{1,2} *$
}

\author{
${ }^{1}$ Department of Obstetrics and Gynaecology, Alexandria, University, Egypt \\ ${ }^{2}$ Fetal Medicine Center (FMC), Alexandria, Egypt
}

Received: 23 February 2016

Revised: 24 February 2016

Accepted: 18 March 2016

\section{*Correspondence: \\ Dr. Ahmed Mohammed Samy El-agwany, \\ E-mail: ahmed.elagwany@alexmed.edu.eg}

Copyright: () the author(s), publisher and licensee Medip Academy. This is an open-access article distributed under the terms of the Creative Commons Attribution Non-Commercial License, which permits unrestricted non-commercial use, distribution, and reproduction in any medium, provided the original work is properly cited.

\begin{abstract}
Background: Preterm birth is the presence of uterine contraction of sufficient frequency and intensity to effect progressive effacement and dilatation of cervix prior to term gestation (between 20 and 37 weeks). The objective of this study was to compare between the different methods of assessment of cervical length (Trans abdominal, trans vaginal, and transperineal) during pregnancy as a possible screening of preterm birth.

Methods: Prospective cohort study was performed on 200 cases who attended at Elshat by hospital. At gestational age from 20 to 26 weeks, there was no significant difference regarding demographic data as (maternal age, parity). The route of examination was started according to urinary bladder fullness at admission. Accordingly, the patient was not instructed to void if she had full bladder, rather we started by transabdominal route. If she had empty bladder at the time she presented we started by transperineal then transvaginal route. The four measurements were compared to each other and the difference between them calculated. The selected sample size was found to be 200 pregnant women.

Results: Transvaginal route gave the longest cervical measurements followed by transperineal route then abdominal route (full bladder) and finally tans abdominal route (semi-full bladder). Our results indicate that there is a significant positive correlation among the four methods of measuring cervical length in that gestational age.

Conclusions: Tran-abdominal assessment could be used initially for cervical length screening, considering the maternal and fetal condition. Then, if the need arises, transvaginal sonography could be used. This step by step approach may be more convenient and useful to both patients and physicians for cervical length screening.
\end{abstract}

Keywords: Sonography, Cervical length, Pregnancy

\section{INTRODUCTION}

Preterm birth is the presence of uterine contraction of sufficient frequency and intensity to effect progressive effacement and dilatation of cervix prior to term gestation (between 20 and 37 weeks). ${ }^{1,2}$

The exact mechanism is unknown but it is believed to include decidual hemorrhage (e.g., abruption mechanical or over distention from multiple gestation or polyhyroamnious), cervical incompetence, uterine distortion (e.g., fibroid uterus) maternal infections (e.g., bacterial vaginosis) and uteroplacental insufficiency (e.g., hypertension, type 1 diabetes, drug abuse, stressful life style and low socioeconomic status).

Cervix is the part of the uterus that connects to vagina it is normally rigid and closed. During pregnancy, the 
cervix gradually soften, decrease in length and dilate as the fetus grows and prepare to give birth. ${ }^{5,6}$

Various factors affecting the cervical length during pregnancy including the biologic difference between women, unknown uterine activity, over distended, uterine infection, inflammation, and incompetent cervix. ${ }^{7}$

Several recent studies have been reported the utility of transabdominal assessment of cervical length. Despite of some limitations including the apparent artificial lengthening when the bladder is filled to enhance imaging, inability to visualize the cervix in some cases, and the difficulty to visualize a shortened cervix. Transabdominal assessment of cervical length may be as accurate and more acceptable to some patient as transvaginal and it may be the technique of choice in some patient in which vaginal examination is limited as in preterm premature rupture of membrane. ${ }^{8,9}$

Transvaginal ultrasonography assessment of cervical length at 22-24 weeks of gestation will provide useful prediction of preterm labour it is useful when transabdominal sonography fails to visualize in high proportion of cases especially those of short cervix. ${ }^{10}$

Another modality is cervical assessment by transperinealtranslabial sonography which done by a curvilinear probe that placed sagittal between labia majora it is less invasive but needs extensive experience sonographers. ${ }^{11,12}$

Krutzman et al examined 206 women at 14-34 of gestation and successfully obtained paired transvaginally and transperineal measurement from all cases they reported correlation coefficient between two measurement $0.959 .^{13,14}$

The study was designed to compare between the different methods of assessment of cervical length (transabdominal, tranasvaginal, and transperineal) during pregnancy as a possible screening of preterm birth.

\section{METHODS}

The study was performed on 200 cases who were attending El-shatby hospital. Inclusion criteria are singleton pregnancy, Patients at (20-26) weeks of pregnancy, cervical dilatation less than $2 \mathrm{~cm}$ and no active uterine contraction. Exclusion criteria are patients with rupture membrane and Patients with cervical cerculage.

After approval of medical ethics committee and signing a written consent all the patients were suspected to: Full history taking and complete general examination.

The patient will undergo ultrasound examination: Abdominal, with the patient placed in the dorsal supine position, Vaginal and transperineal ultrasound, with the patient in the dorsal lithotomy position. The examination started according to the condition of the patient at admission. First vagianlly: the probe was placed in the anterior fornix of the vagina and care will be taken to avoid undue pressure that might artificially lengthen the cervix. The cervical length was measured in the sagittal view and the sonolucent endocervical mucosa will be used as a guide to the true position of the internal os. Then, transperineal ultrasound done: a curvilinear probe was inserted in a latex glove containing ultrasonic gel and covered with water soluble gel and placed sagittally between the labia majora the transducer was moved caudally onto perineum and also laterally or obliquely as necessary then cervical length was obtained. Lastly transabdominal done in two phases: first, with the patient half full bladder $(250-300 \mathrm{cc})$ we taken cervical length. Then, wait some time and take cervical length with the patient full bladder (>300cc) (Figure 1-3).

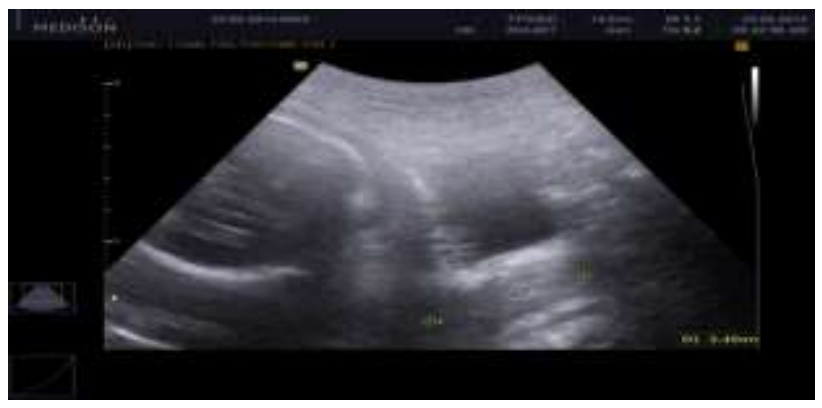

Figure 1: Transabdominal ultrasound assessment of cervical length.

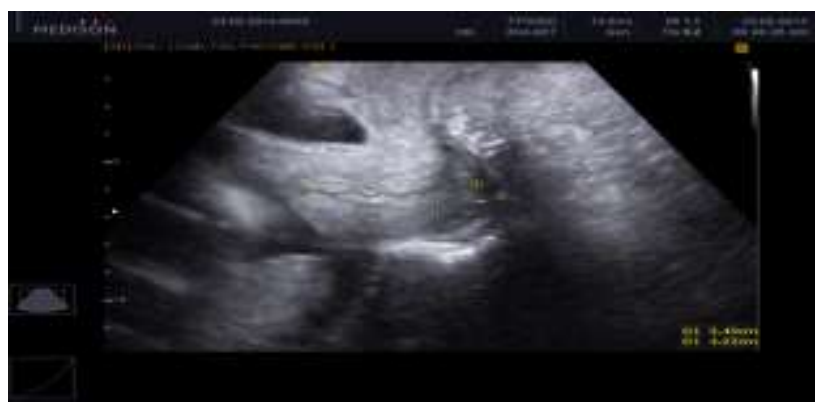

Figure 2: Transperineal ultrasound assessment of cervical length.

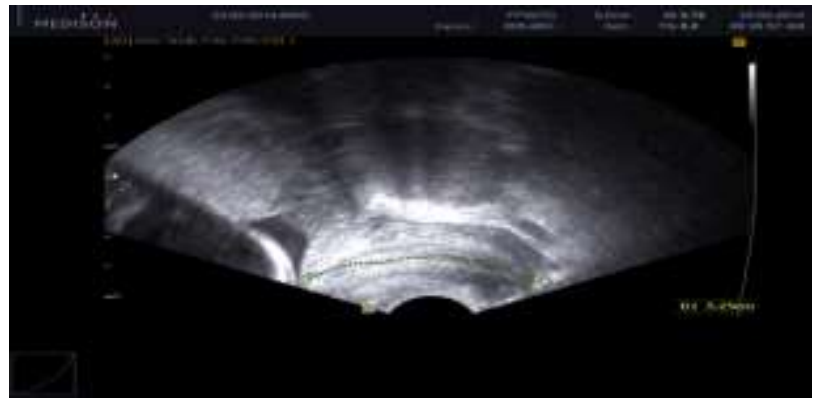

Figure 3: Transvaginal ultrasound assessment of cervical length. 
If the patient came with full or half full we started with abdominal ultrasound examination then ask the patient to empty bladder and continue examination vaginal and transperineal. All the measurement was compared each other and the difference between them calculated.

\section{RESULTS}

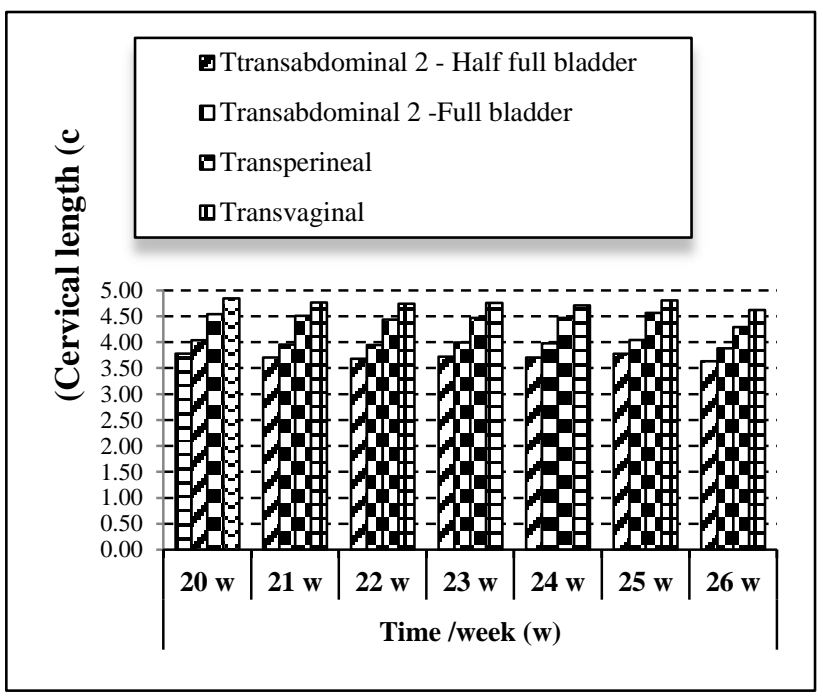

Figure 4: Effect of different methods of sonographic cervical length during pregnancy.

\section{Regression or Curve estimation}

Between Transperineal (x) and Transvaginal (y)

$4^{\text {th }}$ Degree Polynomial Fit:

$\mathrm{y}=54.316313-42.645511 \mathrm{x}+13.165808 \mathrm{x}^{2}-$

$1.7581356 \mathrm{x}^{3}+0.0876744 \mathrm{x}^{4}$

$\mathrm{R}^{2}=0.97$

Between Transabdominal 2-Full bladder (x) and

Transvaginal (y)

Reciprocal Model:

$\mathrm{y}=1 /(0.038587861 \mathrm{x}+0.36504338)$

$\mathrm{R}^{2}=0.95$

Between Transabdominal 2-Half full bladder (x) and

Transvaginal (y)

Reciprocal Model:

$\mathrm{y}=1 /(-0.040004474 \mathrm{x}+0.36019382)$

$\mathrm{R}^{2}=0.96$

\section{Curve estimation or curve fitting}

The relationship between the method of Transperineal as independent variable and the method of Transvaginal as dependent variable represented by equation $4^{\text {th }}$ Degree Polynomial "Y=54.316313-42.645511X+13.165808X2$1.7581356 \mathrm{X} 3+0.0876744 \mathrm{X} 4 "$, where you can predict the values of the Transvaginal by the values of the Transperineal with determining factor equal 0.97 .

Table 1: Examples for prediction of the values of the transvaginal by the values of transperineal, transabdominal full bladder and transabdominal half full bladder for example.

\begin{tabular}{|c|c|c|c|c|c|c|c|c|c|c|c|c|c|}
\hline 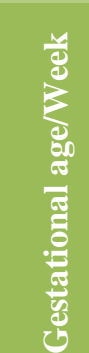 & है & 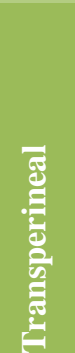 & 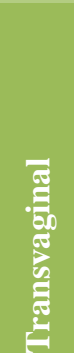 & 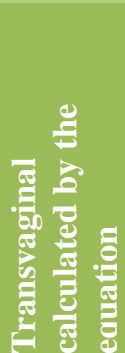 & 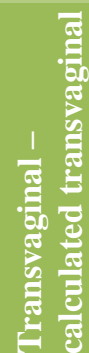 & 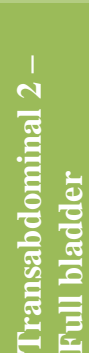 & 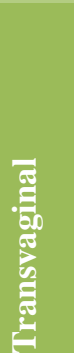 & 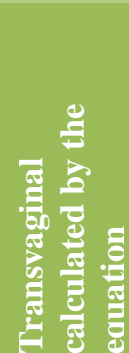 & 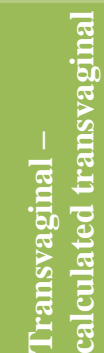 & 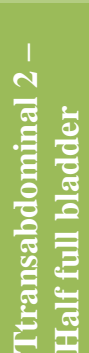 & 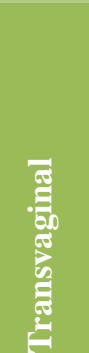 & 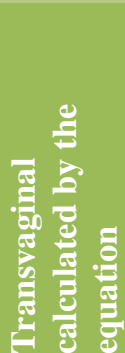 & 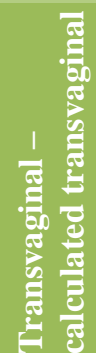 \\
\hline \multirow[b]{2}{*}{20} & 7 & 4.50 & 4.70 & 4.76 & -0.06 & 3.93 & 4.70 & 4.69 & 0.01 & 3.70 & 4.70 & 4.71 & -0.01 \\
\hline & 13 & 4.30 & 4.60 & 4.57 & 0.03 & 3.80 & 4.60 & 4.58 & 0.02 & 3.60 & 4.60 & 4.63 & -0.03 \\
\hline \multirow{2}{*}{21} & 32 & 4.50 & 4.70 & 4.76 & -0.06 & 3.93 & 4.70 & 4.69 & 0.01 & 3.70 & 4.70 & 4.71 & -0.01 \\
\hline & 38 & 4.90 & 5.20 & 5.16 & 0.04 & 4.45 & 5.20 & 5.17 & 0.03 & 4.20 & 5.20 & 5.20 & 0.00 \\
\hline \multirow{2}{*}{22} & 62 & 5.60 & 5.40 & 5.85 & -0.45 & 4.66 & 5.40 & 5.40 & 0.00 & 4.40 & 5.40 & 5.43 & -0.03 \\
\hline & 74 & 4.20 & 4.50 & 4.47 & 0.03 & 3.70 & 4.50 & 4.50 & 0.00 & 3.40 & 4.50 & 4.46 & 0.04 \\
\hline \multirow{2}{*}{23} & 85 & 4.80 & 5.10 & 5.06 & 0.04 & 4.35 & 5.10 & 5.07 & 0.03 & 4.10 & 5.10 & 5.10 & 0.00 \\
\hline & 106 & 4.20 & 4.50 & 4.47 & 0.03 & 3.70 & 4.50 & 4.50 & 0.00 & 3.40 & 4.50 & 4.46 & 0.04 \\
\hline \multirow{2}{*}{24} & 124 & 4.40 & 4.70 & 4.66 & 0.04 & 3.93 & 4.70 & 4.69 & 0.01 & 3.70 & 4.70 & 4.71 & -0.01 \\
\hline & 140 & 4 & 4.40 & 4.39 & 0.01 & 3.55 & 4.40 & 4.38 & 0.0 & 3.30 & 4.40 & 4.38 & 0.02 \\
\hline \multirow{2}{*}{25} & 154 & 4.50 & 4.72 & 4.76 & -0.04 & 4.01 & 4.72 & 4.75 & -0.03 & 3.70 & 4.72 & 4.71 & 0.01 \\
\hline & 167 & 4 & 4.60 & 4.57 & 0.03 & 3.84 & 4.60 & 4.61 & -0. & 3.60 & 4.60 & 4.63 & -0.03 \\
\hline \multirow{2}{*}{26} & 191 & 4.60 & 4.80 & 4.86 & -0.06 & 4.10 & 4.80 & 4.83 & -0.03 & 3.80 & 4.80 & 4.80 & 0.00 \\
\hline & 193 & 4.02 & 4.30 & 4.33 & -0.03 & 3.46 & 4.30 & 4.32 & -0.02 & 3.20 & 4.30 & 4.31 & -0.01 \\
\hline \multicolumn{2}{|c|}{ Average ( 200 case) } & 4.47 & 4.74 & 4.73 & 0.01 & 3.97 & 4.74 & 4.72 & 0.02 & 3.71 & 4.74 & 4.72 & 0.02 \\
\hline
\end{tabular}


The relationship between the method of Transabdominal 2 -Full bladder as independent variable and the method of Transvaginal as dependent variable represented by equation $\mathrm{Y}=1 /(-0.038587861 \mathrm{X}+0.36504338)$, where you can predict the values of the Transvaginal by the values of the Transabdominal 2 -Full bladder with determining factor equal 0.95 .

The relationship between the method of transabdominal 2-Half Full bladder as independent variable and the method of transvaginal as dependent variable represented by equation $Y=1 /(-0.040004474 X+0.36019382)$, where you can predict the values of the transvaginal by the values of the Transabdominal 2-Half Full bladder with determining factor equal 0.96.can predict the values of the transvaginal by the values of transperineal, transabdominal 2-Full bladder and transabdominal 2Half full bladder for example (see Table 1).

\section{DISCUSSION}

Preterm birth is a leading cause of neonatal morbidity and mortality. Previously, medical efforts have focused on the management of prematurity rather than preventing its occurrence, despite advances in obstetric care, fewer advances have been made in primary prevention of preterm birth and effective tocolysis. ${ }^{15,16}$

The rate of preterm birth has not decreased over the past 40 years, with increased prevalence reported in developed countries. For this reason, the focus of preterm birth management has changed from tocolysis to primary prevention. $^{17}$

The aim of this study was to compare between the different methods of assessment of cervical length (transabdominal [full and half-full bladder], trans-vaginal, and transperineal) during pregnancy as a possible screening of preterm birth.

The study was performed on 200 cases who attended at Elshatby hospital. At gestational age from 20 to 26 weeks there was no significant to demographic data as (maternal age, parity).

The route of examination was started according to urinary bladder fullness at admission. Accordingly, the patient was not instructed to void if she had full bladder, rather we started by transabdominal route. If she had empty bladder at the time she presented we started by transperineal then tranasvaginal route, The four measurements were compared to each other and the difference between them calculated.

Trans-vaginal route gave the longest cervical measurements followed by transperineal route then abdominal route (full bladder) and finally tans abdominal route (half-full bladder). Our results indicate that there is a significant positive correlation among the four methods of measuring cervical length in that gestational age.
Hyun et al showed that tranasvaginal cervical length assessment is helpful to predict preterm birth. However, transvaginal sonography could be painful or inconvenient to the patient. In their study trans-abdominal and transvaginal cervical lengths were measured in 255 pregnant women between 20 and 29 gestational weeks. They found that, the mean cervical lengths were not significantly different between the two routes, mean $\pm \mathrm{SD}$, $3.88 \pm 0.73 \mathrm{~cm}$ on transabdominal sonography and $3.93 \pm 0.72 \mathrm{~cm}$ on transvaginal sonography. The $5^{\text {th }}-$ percentile transabdominal cervical length was $26.0 \mathrm{~mm}$, and the transvaginal length was $27.8 \mathrm{~mm} .^{18}$

Agreeing with our work, they stated that trans-abdominal cervical length measurements were correlated with transvaginal measurements overall, and the measured trans-abdominal length is consistently shorter than the transvaginal length in cases with discrepancies. Transabdominal sonography could be used as a cervical length screening tool.

In this study, the relationship between the method of transperineal measurement of cervical length as independent variable $(\mathrm{X})$ and the method of transvaginal as dependent variable $(\mathrm{Y})$ represented by equation $4^{\text {th }}$ degree polynomial:

\section{$Y=54.32-42.64 X+13.1658(X) 2-1.76(X) 3+0.087(X) 4 "$}

Where the values of the transvaginal measurements are calculated by the values of the transperineal measurements with determining factor equal 0.97 .

The relationship between the method of transabdominal measurements with full bladder as independent variable (X) and the method of transvaginal measurements as dependent variable $(\mathrm{Y})$ represented by equation:

$\mathrm{Y}=1 /(-0.038 \mathrm{X}+0.36504338)$

Where values of the transvaginal measurements are calculated by the values of the trans-abdominal the measurements with full bladder with determining factor equal 0.95 .

The relationship between the method of transabdominal measurements with half full bladder as independent variable and the method of transvaginal measurements as dependent variable represented by equation:

$\mathrm{Y}=1 /(-0.04 \mathrm{X}+0.36019382)$

Where the values of the transvaginal measurements are calculated by the values of the transabdominal half full bladder with determining factor equal 0.96 .

The mean cervical length on transabdominal sonography was consistently less than the length on transvaginal sonography, even in the patients with significant discrepancies between the two lengths. This finding 
implies that trans-abdominal sonography may be used safely for the initial measurement of cervical length. Stone et al noted that transabdominal measurements were consistently shorter than transvaginal measurements. They also suggested that transabdominal sonography could be used to assess cervical length in most cases initially. ${ }^{19}$

Determination of the cutoff value for prediction of preterm labor is important for practical use of transabdominal cervical assessment. Stone et al proposed a transabdominal cervical length less than $27 \mathrm{~mm}$ as the cutoff value for indicating preterm labor, which correlates with the $5^{\text {th }}$-percentile transvaginal measurement. ${ }^{1,20}$

In this study, the $5^{\text {th }}$ - and $10^{\text {th }}$-percentile transabdominal measurement values were 26.0 and $30.0 \mathrm{~mm}$, respectively, and the $5^{\text {th }}$-and $10^{\text {th }}$-percentile tranasvaginal values were 27.8 and $30.0 \mathrm{~mm}$. There were 3 cases with cervical lengths less than $25 \mathrm{~mm}(21.0,22.0$, and 24.0 $\mathrm{mm})$ transvaginally, which is generally recognized as being in a high-risk group for preterm birth. Their cervical lengths on transabdominal sonography were 24.0, 25.0, and $25.0 \mathrm{~mm}$. Although for these 3 cases, the tranasvaginal measurements were less than the transabdominal measurements, the transabdominal measurements were all below the $5^{\text {th }}$ percentile; therefore, the cases were positive by transabdominal screening.

The evidence for the clinical application of cervical length screening using transabdominal sonography is still insufficient. It is necessary to determine a transabdominal sonographic measurement threshold and to follow patients until they deliver. However, on the basis of our study, transabdominal assessment could be used initially for cervical length screening, considering the maternal and fetal condition.

Then, if the need arises, tranasvaginal sonography could be used. This step by step approach may be more convenient and useful to both patients and physicians for cervical length screening.

\section{RECOMMENDATIONS}

Future randomized controlled trials are warranted to determine the proper timing for transabdominal cervical length scan for early diagnosis of preterm labor.

\section{CONCLUSIONS}

Transabdominal assessment could be used initially for cervical length screening, considering the maternal and fetal condition. Then, if the need arises, tranasvaginal sonography could be used. This step by step approach may be more convenient and useful to both patients and physicians for cervical length screening.
Funding: No funding sources Conflict of interest: None declared

Ethical approval: The study was approved by the Institutional Ethics Committee

\section{REFERENCES}

1. ACOG practice bulletin. Management of preterm labor. Numbre 43. Int J Gynaecol Obestet 2009; 82(1):127-35.

2. Eden RD, Penka A, Britt DW, Landsberger EJ, Evans MI. Re-evaluating the role of the MFM specialist: lead, follow, or get out of the way. J Maternal Fetal Neonatal Med. 2005;18(4):253-8.

3. Lykke JA, Paidas MJ, Ross JL. Recurring complication in the second pregnancy. Obstet Gynecol. 2009;113(6):1217-24.

4. Iams JD, Goldenberg RL, Meis PJ, Mercer BM, Moawad A, Das A, et al. The length of the cervix and the risk of spontaneous delivery $\mathrm{N}$ Engl J Med. 2002;334:567-72.

5. Heath VCF, Southall TR, Souka AP, Elisseou A, Nicolaides KH. Cervical length at 23 weeks of gestation: prediction of spontaneous preterm delivery Ultrasound Obstet Gynecol. 2010;12:312-7.

6. To MS, Skentou C, Cicero S, Nicolaides KH. Transvaginal and transabdominal ultrasonography of the uterine cervix at 23 weeks of pregnancy: technical aspects I. Ultrasound Obstet Gynecol. 2000;15:292-6.

7. Podobnik M, Bulic M, Smiljanic N, Bistricki J. Ultrasonography in the detection of cervical incompetency. J Clin Ultrasound. 2000;13:383-91.

8. Kurtzman JT, Goldsmith LJ, Gall SA, Spinnato JA. Transvaginal versus transperineal ultrasonography: a blinded comparison in the assessment of cervical length at midgestation. Am J Obstet Gynecol. 2011;179:852-7.

9. Owen J, Neely C, Northen A. Transperineal versus endovaginal ultrasonographic examination of the cervix in the midtrimester: a blinded comparison. Am J Obstet Gynecol. 2009;181:780-3.

10. Iams JD, Goldenberg RL, Meis PJ. The length of the cervix and the risk of spontaneous preterm delivery. National Institute of Child Health and Human Development Maternal Fetal Medicine Unit Network. N Engl J Med. 2000;334:567-72.

11. Iams JD, Johnson FF, Sonek J, Sachs L, Gebauer C, Samuels P. Cervical competence as a continuum: a study of ultrasonographic cervical length and obstetrical performance. Am J Obstet Gynecol 2008; 72:1097-103.

12. Iams JD, Paskos J, Landon MB, Teteris JN, Johnson FF. Cervical sonography in preterm labor. Obstet Gynecol. 2004;84:40.

13. Kurtzman JT, Goldsmith LJ, Gall SA, Spinnato JA. Transvaginal versus transperineal ultrasonography: a blinded comparison in the assessment of cervical length at midgestation. Am J Obstet Gynecol. 2012;179:852-7. 
14. Cicero S, Skentou C, Souka A, To MS, Nicolaides KH. Cervical length at 22-24 weeks' gestation: comparison of transvaginal and transperinealtranslabial ultrasonography. Ultrasound Obstet Gynecol. 2011;17:335-40.

15. Gupta JK, Kleijnen J, Khan KS. Accuracy of cervical transvaginal sonography in predicting preterm birth: a systematic review. Ultrasound Obstet Gynecol 2003;22:305-322.

16. Moroz LA, Simhan HN. Rate of sonographic cervical shortening and the risk of spontaneous preterm birth. Am J Obstet Gynecol. 2012; 206:234:e1-234.

17. Hassan SS, Romero R, Vidyadhari D, Fusey S, Baxter JK, Khandelwal M. et al. Vaginal progesterone reduces the rate of preterm birth in women with a sonographic short cervix: a multicenter, randomized, double-blind, placebocontrolled trial. Ultrasound Obstet Gynecol. 2011;38:18-31.

18. Roh HJ, Ji Y, Jung CH, Jeon GH, Chun S, Cho HJ. Comparison of cervical lengths using transabdominal and transvaginal sonography in midpregnancy. JUM October. 2013;32:1721-8.

19. Stone PR, Chan EH, McCowan LM, Taylor RS, Mitchell JM. Transabdominal scanning of the cervix at the 20-week morphology scan: comparison with transvaginal cervical measurements in a healthy nulliparous population. Aust NZ J Obstet Gynaecol. 2010;50:523-7.

20. McDonald HM, O'Loughlin JA, Jolley P, Vigneswaran R, McDonald PJ. Vaginal infection and preterm labour. BJOG. 1991;98:427-35.

Cite this article as: Awad EA, Dayem TA, Agwany AS. Comparison between different methods of sonographic cervical length assessment during pregnancy. Int J Reprod Contracept Obstet Gynecol 2016;5:1348-53. 